\title{
EVIDENCIAÇÃO DA GESTÃO DE RISCOS DO COSO (2004) NOS RELATÓRIOS DA ADMINISTRAÇÃO DE EMPRESAS BRASILEIRAS COM ADRS
}

\section{1- Vinícius Costa da Silva Zonatto*}

Doutorando em Ciências Contábeis e Administração pela Universidade Regional de Blumenau - FURB, Blumenau/SC, Brasil.

Professor da Faculdade Dom Alberto, Santa Cruz do Sul/RS, Brasil.

viniciuszonatto@gmail.com

http://lattes.cnpq.br/1916486402947867

\section{2- Ilse Maria Beuren}

Doutora em Controladoria e Contabilidade pela Faculdade de Economia, Administração e Contabilidade da Universidade de São Paulo - FEA/USP, São Paulo/SP, Brasil.

Professora do Programa de Pós-Graduação em Ciências Contábeis da Universidade Regional de Blumenau PPGCC/FURB, Blumenau/SC, Brasil

ilse@furb.br

http://lattes.cnpq.br/4514517594315817 


\title{
EVIDENCIAÇÃO DA GESTÃO DE RISCOS DO COSO (2004) NOS RELATÓRIOS DA ADMINISTRAÇÃO DE EMPRESAS BRASILEIRAS COM ADRS
}

\section{RESUMO}

O estudo objetiva analisar o conteúdo de evidenciação da gestão de riscos, tendo como referência a metodologia do Committee of Sponsoring Organizations of the Treadway Commission (COSO) (2004), nos relatórios da administração das empresas brasileiras com emissão de American Depositary Receipt (ADRs) na Bolsa de Valores de Nova York (NYSE). Estudo descritivo foi realizado por meio de pesquisa documental, utilizando-se da técnica da análise de conteúdo nos relatórios da administração de 28 empresas, tendo como unidade de registro o termo risco. Foram identificados 400 termos relacionados à gestão de riscos em ambientes de controle. $\mathrm{O}$ ambiente que apresenta maior evidenciação de termos relacionados à gestão de riscos é o ambiente de controle, e o menor, resposta ao risco. Conclui-se que não há uniformidade nas informações divulgadas pelas empresas a respeito das práticas de gestão de riscos. Em geral, divulgam ações relativas às atividades de controle e identificação de riscos, mas não indicam como respondem a estes riscos.

\section{Palavras-Chave}

Evidenciação; gestão de riscos; coso; relatório da administração; empresas com adrs.

\section{RISK MANAGEMENT OF COSO (2004) DISCLOSED ON THE ADMINISTRATION REPORTS OF BRAZILIAN COMPANIES ISSUING ADRS}

\begin{abstract}
The goal of this study is analyze the content of the risk management disclosed, having as reference the methodology of Committee of Sponsoring Organizations of the Treadway Commission (COSO) (2004), disclosed on the administration reports of Brazilian companies issuing American Depositary Receipts (ADRs) in the New York Stock Exchange (NYSE). A descriptive study was conducted through documental research, using the technique of content analysis on the administration reports of 28 companies, having as unit record the term risk. Were identified 400 terms related to risk management in control environments. The environment that has more disclosure of terms related to risk management is the control environment, and less, risk response. It was concluded that there is no uniformity in the information disclosed by the companies about the risk management practices. In general, they disclose actions related to the control activities and risks identification, but do not indicate how they respond to these risks.
\end{abstract}

\section{Keywords}

Disclosure; risk management; coso; administration report; companies issuing adrs. 


\section{Introdução}

Para os investidores, a busca pela garantia do retorno sobre o investimento é fator fundamental na aplicação de seus recursos. Segundo Quinteiro (2004, p. 1), "a evidenciação de informações contábeis relevantes reduz a assimetria de informações no mercado e, conseqüentemente, o risco de os investidores cometerem erros em suas decisões, aumentando a atração de capitais". Neste sentido, um item que merece destaque na evidenciação das demonstrações contábeis refere-se à gestão de riscos das organizações. A gestão focada para o alcance dos objetivos da empresa permite ao gestor o monitoramento das atividades e a identificação de novas oportunidades ou de ameaças às quais a entidade possa estar exposta. As ameaças representam riscos à organização.

Os riscos podem resultar em perdas à organização, mas também há riscos que acabam se tornando uma oportunidade para o empreendimento. A gestão baseada em riscos requer a avaliação prévia dos objetivos da empresa frente aos ambientes interno e externo, bem como eventuais probabilidades de ocorrências que poderão prejudicar o desempenho da empresa e o alcance de seus objetivos. 0 gerenciamento de riscos deve ser realizado com a utilização de modelos de gestão de riscos. Estes modelos apresentam estruturas que orientam os gestores no processo de identificação, monitoramento e controle dos riscos.

Dentre os modelos mais aceitos para o gerenciamento de riscos e controle interno, Maia et al. (2005) destacam o Committee of Sponsoring Organizations of the Treadway Commission (COSO) - Comitê das Organizações Patrocinadoras, o Criteria of Control Committee of Canadian Institute of Chartered Accountants ( $\mathrm{CoCo}$ ) - Critério de Controle do Instituto de Contadores do Canadá, o Committee on Corporate Governance of the Institute of Chartered Accountants in England \& Wales (Turnbull Report) - Código Combinado de Governança Corporativa do Instituto de Contabilistas Certificados da Inglaterra, e o King Committee on Corporate Governance (King Report) - Comitê de Governança Corporativa da África do Sul.

Segundo os autores, um dos mais conhecidos e aceitos mundialmente é o modelo COSO. Trata-se de uma entidade sem fins lucrativos que desenvolve ações visando à melhoria das demonstrações financeiras das organizações. Criado em 1992, seu enfoque principal está voltado aos controles internos das organizações (COSO 1992). O modelo COSO apresenta-se como uma das alternativas para o estabelecimento de uma seqüência de eventos que devem ser observados na gestão de riscos das organizações. Propõe a classificação dos objetivos das empresas em quatro categorias possíveis, com a finalidade de possibilitar aos níveis de gestão mais altos da entidade visualizar, separadamente, os aspectos da gestão de riscos.

Nas empresas brasileiras com emissão de American Depositary Receipt (ADR), a preocupação com a gestão de riscos deve ser ainda maior, visto que suas ações são negociadas na New York Stock Exchange (NYSE), que exige o gerenciamento de riscos dessas organizações. A FIPECAFI (2000) adverte a respeito da necessidade informacional no mercado de capitais, recomendando a ênfase à evidenciação de todas as informações que possibilitem aos investidores uma avaliação do patrimônio da empresa, bem como suas projeções futuras. Isto vem ao encontro da expectativa dos investidores e das práticas de disclosxure voluntário.

A evidenciação da gestão de riscos pode ser objeto do relatório da administração. De acordo com Silva, Rodrigues e Abreu (2004, p. 7), o relatório da administração "é um relatório narrativo, no qual a empresa tem certa liberdade de apresentar notícias da empresa". Além de obrigatório pela Lei das Sociedades por Ações, Lei №. 6.404/76, e recomendado pela Comissão de Valores Mobiliários, no Parecer de Orientação №. 15/87, é considerado por vários pesquisadores como fundamental para o disclosure das organizações.

Com base no exposto elaborou-se a seguinte questão de pesquisa: Qual é o conteúdo da gestão de riscos evidenciado, tendo como referência a metodologia do Committee of Sponsoring Organizations of the Treadway Commission (COSO) (2004), nos relatórios da administração das empresas brasileiras com emissão de ADRs na Bolsa de Valores de Nova York (NYSE). Assim o objetivo do estudo é analisar o conteúdo de evidenciação da gestão de riscos, considerando a metodologia do Committee of Sponsoring Organizations of the Treadway Commission (COSO) (2004), nos relatórios da administração das empresas brasileiras com emissão de ADRs na Bolsa de Valores de Nova York (NYSE).

A pesquisa justifica-se pela relevância da evidenciação da gestão de riscos ao mercado de capitais, visto que tais informações quando divulgadas passam a subsidiar a análise e a escolha de novas oportunidades de negócios por parte dos investidores. Quinteiro (2004) destaca a relevância da divulgação de 
informações do negócio da empresa, a fim de assegurar a credibilidade da organização para com o investidor. A gestão de riscos em ambientes de controle ainda é um assunto precisa ser mais explorado, principalmente a sua evidenciação em diferentes documentos disponibilizados aos usuários da informação contábil.

\section{Evidenciação Compulsória e Voluntária}

O termo evidenciação, de acordo com Goulart (2003, p. 58), pode ser entendido como “o oposto de fechamento, significando a abertura da empresa por meio da divulgação das informações, garantindo a transparência corporativa diante do público e dos participantes do mercado". Em inglês o termo disclosure significa: dis - negação, discordar; e closure - fechar, omitir. Depreende-se que a evidenciação (disclosure) compreende o conjunto de informações divulgadas pelas organizações.

De modo mais específico, Niyama e Gomes (2006, p. 65) citam que “disclosure (...) diz respeito à qualidade das informações de caráter financeiro e econômico, sobre as operações, recursos e obrigações de uma entidade, que sejam úteis aos usuários das demonstrações contábeis". ludícibus (2004, p. 123) explica que "o disclosure está ligado aos objetivos da contabilidade da empresa, ao garantir as informações diferenciadas para os vários tipos de usuários".

A FIPECAFI (2000, p. 43) adverte a respeito da necessidade informacional do mercado de capitais. Recomenda às empresas que dêem maior "ênfase à evidenciação de todas as informações que permitem a avaliação da sua situação patrimonial e das mutações desse seu patrimônio e, além disso, que possibilitem a realização de inferências perante o futuro". Esta recomendação vem ao encontro das características da informação contábil destacadas pelo CPC (2008): compreensibilidade, relevância, confiabilidade e comparabilidade. Sem estas características, as informações não conseguem dar suporte o processo decisório.

O detalhamento de informações contidas nas demonstrações contábeis pode ser efetuado no relatório da administração, nas notas explicativas e outros documentos de evidenciação disponibilizados pela empresa ao público. Depreende-se que a evidenciação não deve apenas compreender itens obrigatórios (evidenciação compulsória), mas todos os demais fatos relevantes que influenciam as atividades, denominado de evidenciação voluntária.

A Lei das Sociedades por Ações, Lei n. 6.404/76, alterada pela Lei n. 11.638/07, exige das companhias abertas, a elaboração e divulgação dentre as demonstrações contábeis obrigatórias, o relatório da administração, que também é recomendado no Brasil pela Comissão de Valores Mobiliários (CVM), por meio do Parecer de Orientação n. 15/87. O relatório da administração serve para as empresas divulgarem tanto as informações quantitativas, quanto as qualitativas, sejam elas obrigatórias ou voluntárias, sobre a gestão dos seus negócios.

Segundo Alencar (2007), a evidenciação voluntária de informações permite agregar valor às organizações, dando maior credibilidade destas empresas ao mercado de capitais. Contudo, o autor destaca que na prática, as evidências encontradas de disclosure voluntário são descritas apenas como vantajosas para as empresas, não sendo evidenciadas informações que possam trazer prejuízos à organização. Sob este aspecto, Goulart (2003) alerta para a omissão de informações, o que poderá acarretar, posteriormente, prejuízos às organizações.

Sobre evidenciação das informações relativas ao negócio das organizações, Hendriksen e Van Breda (1999, p. 524) e ludícibus (2004, p. 126) destacam algumas formas para a melhoria do disclosure das organizações: a) forma e apresentação das demonstrações contábeis; b) informação entre parênteses; c) notas explicativas; d) quadros e demonstrativos suplementares; e) comentários do auditor; e f) relatório da administração.

As abordagens dos autores demonstram as várias formas de como as empresas poderão evidenciar informações relevantes sobre seus negócios, aumentando a sua credibilidade junto aos investidores e ao mercado de capitais. Segundo ludícibus (2004), no relatório da administração as empresas podem evidenciar tanto suas informações quantitativas, ressaltando dados relevantes, como informações qualitativas, aumentando o nível de evidenciação da administração. Denota-se que o relatório da administração possui importante papel na relação das organizações com os investidores e o mercado de capitais. 
A FIPECAFI (2000, p. 398) ressalta que o relatório da administração, objeto de análise desse estudo, "representa um necessário e importante complemento às demonstrações financeiras publicadas por uma empresa, em termos de permitir o fornecimento de dados e informações adicionais que sejam úteis aos usuários no seu julgamento e processo de tomada de decisões". Portanto, o relatório da administração é uma alternativa para a evidenciação das práticas empresariais em conformidade ao previsto no COSO (2004) sobre os componentes do gerenciamento de riscos.

\section{Componentes do Gerenciamento de Riscos do Coso (2004)}

Gerenciar riscos significa gerenciar possibilidades de perdas ou redução de lucros. A gestão baseada em riscos requer a avaliação prévia dos objetivos da empresa frente aos ambientes interno e externo, bem como eventuais probabilidades de ocorrências que possam prejudicar o desempenho da empresa e o alcance de seus objetivos. A empresa busca a maximização dos seus resultados e o incremento nos lucros. Após a determinação dos seus objetivos, inicia-se o processo de implementação das ações que determinará o foco das atividades da organização. Os resultados serão alcançados se nenhum fator adverso interferir nessas operações. Por isso há necessidade de controle dessas atividades.

Beuren (2002) explica que a necessidade de controles é fundamental no gerenciamento das organizações. O controle das atividades permite ao gestor avaliar se as ações implantadas estão proporcionando os benefícios esperados para a empresa. Para que o gestor possa gerenciar riscos, é necessário o estabelecimento de um ambiente de controle. Estratégias são definidas, mapas podem ser criados, mas é necessário um modelo que norteie a gestão de riscos na organização. Jorion (1997, p. 4) define o gerenciamento de risco como "o processo pelo qual várias exposições são identificadas, mensuradas e controladas".

O Committee of Sponsoring Organizations of the Treadway Commission (COSO) publicou em 2004, através do American Institute of Certified Public Accountants (A/CPA), um trabalho sob o título Enterprise Risk Management - Integrated Framework. No referido documento estabeleceu uma seqüência de eventos que deve ser observada na gestão de processos em ambiente de controle, conforme demonstrado no Quadro 1.

Quadro 1 - Componentes do gerenciamento de riscos corporativos previstos no COSO

\begin{tabular}{l|ll} 
Componentes & Descrição
\end{tabular}

\begin{tabular}{|c|c|}
\hline & \\
\hline $\begin{array}{l}\text { Ambiente interno } \\
\text { (ou de controle) }\end{array}$ & $\begin{array}{l}\text { A administração estabelece uma filosofia quanto ao tratamento de riscos e estabelece um limite de apetite a risco. } \\
\text { O ambiente interno determina os conceitos básicos sobre a forma como os riscos e os controles serão vistos e } \\
\text { abordados pelos empregados da organização. O coração de toda organização fundamenta-se em seu corpo de } \\
\text { empregados, isto é, nos atributos individuais, inclusive a integridade, os valores éticos e a competência, bem } \\
\text { como no ambiente em que atuam. }\end{array}$ \\
\hline $\begin{array}{l}\text { Definição (ou } \\
\text { fixação) de } \\
\text { objetivos }\end{array}$ & $\begin{array}{l}\text { Os objetivos devem existir antes que a administração identifique as situações em potencial que poderão afetar a } \\
\text { realização destes. O gerenciamento de riscos corporativos assegura que a administração adote um processo para } \\
\text { estabelecer objetivos e que os escolhidos propiciem suporte, alinhem-se com a missão da organização e sejam } \\
\text { compatíveis com o apetite a risco. }\end{array}$ \\
\hline $\begin{array}{l}\text { Identificação de } \\
\text { riscos (ou } \\
\text { eventos) }\end{array}$ & $\begin{array}{l}\text { Os eventos em potencial que podem impactar a organização devem ser identificados, uma vez que esses } \\
\text { possíveis eventos, gerados por fontes internas ou externas, afetam a realização dos objetivos. Durante o } \\
\text { processo de identificação de eventos, estes poderão ser diferenciados em riscos, oportunidades, ou ambos. As } \\
\text { oportunidades são canalizadas à alta administração, que definirá as estratégias ou os objetivos. }\end{array}$ \\
\hline $\begin{array}{l}\text { Avaliação de } \\
\text { riscos }\end{array}$ & $\begin{array}{l}\text { Os riscos identificados são analisados com a finalidade de determinar a forma como serão administrados e, } \\
\text { depois, serão associados aos objetivos que podem influenciar. Avaliam-se os riscos considerando seus efeitos } \\
\text { inerentes e residuais, bem como sua probabilidade e seu impacto. }\end{array}$ \\
\hline $\begin{array}{l}\text { Resposta aos } \\
\text { riscos }\end{array}$ & $\begin{array}{l}\text { Os empregados identificam e avaliam as possíveis respostas aos riscos: evitar, aceitar, reduzir ou compartilhar. A } \\
\text { administração seleciona o conjunto de ações destinadas a alinhar os riscos às respectivas tolerâncias e ao apetite } \\
\text { a risco. }\end{array}$ \\
\hline $\begin{array}{l}\text { Atividades de } \\
\text { controle }\end{array}$ & $\begin{array}{l}\text { Políticas e procedimentos são estabelecidos e implementados para assegurar que as respostas aos riscos } \\
\text { selecionados pela administração sejam executadas com eficácia. }\end{array}$ \\
\hline $\begin{array}{l}\text { Informações e } \\
\text { comunicações }\end{array}$ & $\begin{array}{l}\text { A forma e o prazo em que as informações relevantes são identificadas, colhidas e comunicadas permite que as } \\
\text { pessoas cumpram com suas atribuições. Para identificar, avaliar e responder ao risco, a organização necessita } \\
\text { das informações em todos os níveis hierárquicos. A comunicação eficaz ocorre quando esta flui na organização } \\
\text { em todas as direções, e quando os empregados recebem informações claras quanto às suas funções e } \\
\text { responsabilidades. }\end{array}$ \\
\hline Monitoramento & $\begin{array}{l}\text { A integridade do processo de gerenciamento de riscos corporativos é monitorada e as modificações necessárias } \\
\text { são realizadas. Desse modo, a organização poderá reagir ativamente e mudar segundo as circunstâncias. O } \\
\text { monitoramento é realizado por meio de atividades gerenciais contínuas, avaliações independentes ou uma } \\
\text { combinação desses dois procedimentos. }\end{array}$ \\
\hline
\end{tabular}

Fonte: COSO (2004, p. 22). 
O modelo COSO não objetiva a eliminação total dos riscos, mas a administração destes eventos em níveis aceitáveis pela organização. O foco da gestão de riscos está direcionado aos eventos que possam afetar o alcance dos resultados esperados pela organização. O intuito é que os gestores levem em consideração os riscos a que as empresas estão expostas e avaliar os controles necessários para o gerenciamento destes riscos e, por sua vez, se estes se encontram ativos.

\section{Métodos e Procedimentos da Pesquisa}

Esta pesquisa caracteriza-se como descritiva. De acordo com Gil (2002), ela tem como principal finalidade descrever características de determinada população ou fenômeno ou o estabelecimento de relações entre as variáveis. Para a realização da pesquisa descritiva, realizou-se análise documental. Gil (2002, p. 45) explica que a análise documental “baseia-se em materiais que ainda não receberam um tratamento analítico ou que podem ser reelaborados de acordo com os objetivos da pesquisa".

A população do estudo compreendeu as 32 empresas brasileiras com emissão de American Depositary Receipt (ADR) na Bolsa de Valores de Nova York (NYSE). Inicialmente buscou-se identificar no site da NYSE (www.nyse.com) as empresas brasileiras emitentes de ADRs. Na seqüência pesquisou-se no mesmo site informações relativas às características das empresas divulgadas nesta página eletrônica. Neste momento, excluiu-se a empresa Ultrapar Participações S.A., pelo fato das informações relativas a esta empresa estarem indisponíveis.

No estudo também foram descartadas as empresas que iniciaram a emissão de ADRs a partir de 2007 , pressupondo que não possuem histórico de gestão de riscos. Assim foram excluídas duas empresas, a Cosan Ltda. e a Gafisa S.A. Também foi excluída da amostra da pesquisa a Petrobrás - Petróleo Brasileiro S.A. Esta foi excluída da análise pelo fato do arquivo do relatório da administração, disponibilizado no site da Bovespa (www.bovespa.com.br), estar corrompido, não podendo assim ser acessado. Portanto, a amostra da pesquisa resultou em 28 empresas brasileiras que emitiram ADRs antes de 2007. Destaca-se que a amostra escolhida para a realização desta pesquisa é intencional, ou seja, não-probabilística.

No site da Bovespa (www.bovespa.com.br) foram capturados os relatórios da administração destas empresas, relativos ao exercício de 2007. Foram obtidos com êxito os relatórios de administração das 28 empresas que compõem a amostra da pesquisa. Em seguida efetuou-se a análise de conteúdo. A análise de conteúdo, conforme Bardin (1977, p. 46), objetiva “a manipulação de mensagens (conteúdo e expressão desse conteúdo), para evidenciar os indicadores que permitam inferir sobre uma outra realidade que não a da mensagem". O autor explica que a análise de conteúdo compreende um conjunto de técnicas de investigação que tem por finalidade a análise das comunicações.

Para Freitas e Janissek (2000, p. 37), análise de conteúdo “é um método de observação indireto, já que é a expressão verbal ou escrita do respondente que será observada". Por meio da análise de conteúdo procedeu-se à análise dos relatórios da administração das empresas pesquisadas do ano de 2007 . Para tanto, primeiramente delimitou-se como unidade de registro o termo risco. Como exemplo de termo risco pode-se citar a "administração dos riscos intrínsecos as atividades da empresa". A unidade de registro termo foi considerada para verificar os termos em si e a predominância do termo risco nos RA de 2007. Bardin (1977, p. 104) define unidade de registro como "a unidade de significação a codificar e corresponde ao segmento de conteúdo a considerar como unidade de base, visando à categorização e contagem freqüencial. A unidade de registro pode ser de natureza e de dimensões muito variáveis". Unidades de registro "podem ser: a palavra, a frase, o minuto, o centímetro quadrado" (BARDIN, 1977, p. 36).

Para analisar o conteúdo de evidenciação da gestão de riscos nos relatórios da administração, tendo como referência a metodologia do COSO (2004), definiu-se a frase como unidade de análise do contexto. Um exemplo de frase de evidenciação da gestão de riscos em ambientes do coso é: “A companhia mantém uma área de gestão de riscos responsável por coordenar o processo e disseminar a cultura do gerenciamento de riscos em todos os níveis internos" (ARACRUZ CELULOSE S. A., 2007). Segundo Freitas, Cunha Júnior e Moscarola (1997, p. 8), a frase caracteriza-se como unidade de contexto, "por ser mais sutil e flexível do que a unidade de registro e não se ampara em quantificação rigorosa. Trata-se de segmento mais amplo de conteúdo, ao qual se refere quando se deseja compreender a unidade de registro". Portanto, consideraram-se como unidade de registro o termo e como unidade de contexto a frase. 


\section{Descrição e Análise dos Dados}

Nesta seção, inicialmente descrevem-se trechos da evidenciação da gestão de riscos dos ambientes do COSO nos relatórios da administração (RA) tendo como referência os componentes expostos no Quadro 1. Em seguida apresenta-se termos de evidenciação da gestão de riscos por componente do COSO.

\subsection{Trechos da Evidenciação da Gestão de Riscos dos Ambientes do COSO nos RA}

Os oito componentes da gestão de riscos estabelecidos pelo COSO em 2004 são: ambiente interno, definição (fixação) de objetivos, identificação dos riscos, avaliação dos riscos, resposta ao risco, atividades de controle, informação e comunicação e monitoramento. Os componentes do COSO são apresentados na seqüência em conjunto com alguns trechos da evidenciação da gestão de riscos selecionados nos RA das empresas pesquisadas.

\subsubsection{Ambiente interno (de controle)}

De acordo com o COSO (2004), o ambiente de controle é o alicerce de todos os componentes do gerenciamento de riscos da organização. Nele definem-se a filosofia de administração de riscos da empresa, o apetite ao risco, as responsabilidades do conselho de administração, a integridade e os valores éticos que norteiam as atividades da empresa, o compromisso com a competência, a estrutura organizacional, a designação de autoridade e responsabilidade dentro da organização, as políticas e práticas de recursos humanos e as diferenças no ambiente interno, bem como suas implicações.

No Quadro 2 apresentam-se trechos dos RA das empresas Aracruz Celulose S.A., Brasil Telecom S.A. e Companhia Paranaense de Energia (COPEL), para exemplificar o uso do ambiente interno (de controle) na evidenciação da gestão de riscos previstos no COSO.

Quadro 2 - Componente do gerenciamento de riscos do COSO - Ambiente interno (de controle)

\begin{tabular}{|c|c|}
\hline $\begin{array}{l}1^{\circ} \text { Componente } \\
\text { do COSO }\end{array}$ & Exemplos de trechos dos RA das empresas pesquisadas \\
\hline \multirow{3}{*}{$\begin{array}{l}\text { Ambiente interno } \\
\text { (de controle) }\end{array}$} & $\begin{array}{l}\text { "A Aracruz considera a gestão de riscos um instrumento essencial para otimizar o uso do capital e } \\
\text { selecionar as melhores oportunidades de negócios, de forma a obter a melhor relação risco x retorno } \\
\text { para seus acionistas. A Companhia mantém uma área de Gestão de Riscos responsável por coordenar } \\
\text { o processo e disseminar a cultura do gerenciamento de riscos em todos os níveis internos" (ARACRUZ } \\
\text { CELULOSE S. A., 2007) [Grifo nosso]. }\end{array}$ \\
\hline & $\begin{array}{l}\text { "Com a reforma do estatuto social, cresceu o número de diretores estatutários de quatro para seis e } \\
\text { instituiu-se a decisão colegiada, com reuniões semanais. Este modelo aumenta a diversidade de } \\
\text { pontos de vista nas discussões, reduz o nível de risco e melhora a transparência do processo decisório } \\
\text { da Companhia" (BRASIL TELECOM, 2007) [Grifo nosso]. }\end{array}$ \\
\hline & $\begin{array}{l}\text { "Com base na implementação do Modelo de Gestão Integrada de Riscos Corporativos e atendendo a } \\
\text { Norma de Política Copel - NPC n. 0306, de 04.12.2006 - "Política de Controle e Gestão de Riscos na } \\
\text { Copel", a Companhia pretende: a) mapear os principais riscos corporativos e definir as estratégias e } \\
\text { metas empresariais de curto, médio e longo prazo para as dimensões econômica, social e ambiental, } \\
\text { de forma integrada; e b) identificar os principais impactos, riscos e oportunidades sobre a } \\
\text { sustentabilidade e os efeitos em relação às partes interessadas" (COPEL, 2007) [Grifo nosso]. }\end{array}$ \\
\hline
\end{tabular}

Fonte: dados da pesquisa.

No RA da Aracruz constata-se a preocupação com a evidenciação da gestão de riscos a que a entidade está exposta. A empresa informa que possui uma estrutura formalmente definida, responsável pelo processo de gerenciamento e disseminação da cultura de gestão de riscos em toda a organização, relacionando ainda estes fatores à expectativa de retorno dos acionistas.

A administração da empresa Brasil Telecom também se preocupa em demonstrar aos usuários de suas informações contábeis, que está se adequando às novas exigências do mercado de capitais. Ao adotar uma estratégia de gestão focada no processo decisório, transmite para seus acionistas a preocupação com a avaliação criteriosa dos fatores que influenciam seus negócios, estabelecendo assim uma política transparente de gestão de riscos.

No caso da empresa COPEL, a administração evidencia que a gestão de riscos está devidamente regulamentada na organização e se enquadra nas determinações estabelecidas em reunião do conselho de administração. A empresa também destaca os objetivos da gestão de riscos para curto, médio e longo prazo, bem como sua preocupação em identificar os impactos e efeitos dos riscos às partes interessadas. 
Ao utilizar o ambiente de controle do COSO (2004), a administração estabelece uma seqüência de eventos que possibilita a gestão de riscos focada no alcance dos objetivos da organização. Divulgando tais informações em seu relatório da administração, reconhece a necessidade de evidenciar a gestão de riscos inerente às atividades da empresa. Silva (2005) explica que o ambiente de controle é onde os gestores determinam os objetivos da organização e as ações necessárias para o alcance desses objetivos. Nesta etapa a organização é avaliada como um todo, considerando fatores internos e externos que possam ameaçar o alcance dos resultados.

\subsubsection{Definição (fixação) de objetivos}

A segunda etapa do processo de gerenciamento de riscos estabelecidos pela metodologia do COSO (2004) é a definição de objetivos da empresa. De acordo com Souza (2007, p. 27), a definição de objetivos é "uma condição para a identificação de eventos, para a avaliação de riscos e para a resposta ao risco, que são os elementos seguintes da estrutura do COSO 2004". Ressalta que "primeiro devem existir objetivos para que a administração da entidade possa identificar os riscos e dessa forma adotar ações necessárias para mitigá-los".

No Quadro 3 apresentam-se trechos dos RA do Banco Bradesco S.A. e da Companhia Siderúrgica Nacional (CSN), para exemplificar o uso da definição de objetivos na evidenciação da gestão de riscos previstos no COSO.

Quadro 3 - Componente do gerenciamento de riscos do COSO - Definição (Fixação) de objetivos

\begin{tabular}{|c|c|}
\hline $\begin{array}{l}2^{\circ} \text { Componente } \\
\text { do COSO }\end{array}$ & Exemplos de trechos dos RA das empresas pesquisadas \\
\hline \multirow{3}{*}{$\begin{array}{l}\text { Definição (Fixação) } \\
\text { de objetivos }\end{array}$} & $\begin{array}{l}\text { "Três metas de maior amplitude são priorizadas no planejamento estratégico: a) crescer } \\
\text { organicamente }[\ldots] ; \text { b) identificar e avaliar riscos intrínsecos às atividades, aplicando controles } \\
\text { adequados e níveis aceitáveis nas operações; c) parceria com o mercado de capitais [...]" } \\
\text { (BRADESCO, 2007) [Grifo nosso]. }\end{array}$ \\
\hline & $\begin{array}{l}\text { "A CSN dispõe de serviços de Auditoria Interna, com atuação independente, conforme definido no } \\
\text { Estatuto da Empresa. Realiza exames, análises, levantamentos e comprovações, com adoção de } \\
\text { procedimentos de auditoria geralmente aceitos, em todas as Empresas CSN, com objetivo de avaliar a } \\
\text { integridade, adequação, eficácia e economicidade dos processos, bem como a efetividade dos } \\
\text { controles internos" (CSN, 2007) [Grifo nosso]. }\end{array}$ \\
\hline & $\begin{array}{l}\text { "Monitorar os riscos das atividades de controles internos e do ambiente corporativo (Governança), bem } \\
\text { como os requeridos pela Lei Sarbanes-Oxley, com segurança, uniformidade e pontualidade, de forma } \\
\text { a manter a administração da CSN, seus acionistas e órgãos reguladores adequadamente informados } \\
\text { sobre os riscos de negócio (estratégicos), de controle e financeiros da Companhia e atuando para a } \\
\text { contínua melhoria dos seus controles internos" (CSN, 2007) [Grifo nosso]. }\end{array}$ \\
\hline
\end{tabular}

Fonte: dados da pesquisa.

Nota-se a preocupação da administração do Bradesco em destacar que um dos seus objetivos estratégicos está relacionado à gestão de riscos corporativos. A empresa tem por meta maior amplitude para identificar e avaliar todos os riscos inerentes à sua atividade, a fim de estabelecer os controles necessários para trazê-los para níveis aceitáveis de exposição.

No RA da empresa CSN verifica-se a existência dos objetivos de conformidade. Os acionistas estabeleceram em assembléia e regularam no estatuto social sua preocupação com a realização de exames, análises e comprovações, das informações geradas sobre o negócio da empresa. Por meio de realização de auditoria interna, com atuação independente, a empresa busca assegurar a conformidade de suas informações financeiras.

A administração da empresa CSN foi a única que destacou os objetivos de relatórios estabelecidos pelo COSO. Ao evidenciar seus objetivos de conformidade ao atendimento às exigências estabelecidas pela Lei Sarbanes $O x / e y(S O X)$, a empresa também ressalta a importância da geração de informações não só para os órgãos reguladores, mas também para gestores e acionistas.

O COSO (2004) estabelece quatro categorias de objetivos existentes numa organização: objetivos estratégicos, objetivos de conformidade, objetivos de relatórios e objetivos de operações. Estabelecidos os objetivos da empresa, cabe identificar eventos potenciais que possam ameaçar o alcance dos resultados esperados. 


\subsubsection{Identificação dos riscos}

O processo de identificação de riscos decorre da análise de eventos potenciais relacionados aos objetivos da empresa. Os impactos destes eventos podem ser positivos ou negativos. Os eventos positivos representam oportunidades a serem exploradas. Já os eventos negativos são denominados de riscos.

No Quadro 4 apresentam-se trechos dos RA da empresas Empresa brasileira de Aeronáutica (EMBRAER), Companhia Paranaense de Energia (COPEL) e Perdigão S.A., para exemplificar o uso da identificação de riscos na evidenciação da gestão de riscos do $\cos O$.

Quadro 4 - Componente do gerenciamento de riscos do COSO - Identificação dos riscos

\begin{tabular}{|c|c|}
\hline $3^{\circ}$ Componente & Exemplos de trechos dos RA das empresas pesquisadas \\
\hline \multirow{3}{*}{$\begin{array}{l}\text { Identificação } \\
\text { dos riscos }\end{array}$} & $\begin{array}{l}\text { "[...] a Embraer criou em } 2007 \text { uma área de Controles e Riscos que engloba o monitoramento de todos os riscos a } \\
\text { que a Empresa está exposta como: Riscos Estratégicos, Riscos para as Demonstrações Financeiras, Riscos } \\
\text { Econômico-Financeiros, Riscos ao Meio Ambiente, Riscos Operacionais e Riscos de Conformidade" (EMBRAER, } \\
\text { 2007) [Grifo nosso]. }\end{array}$ \\
\hline & $\begin{array}{l}\text { "Os administradores buscam, dessa forma, contribuir para a perenidade da Empresa, com visão de longo prazo na } \\
\text { busca de sustentabilidade econômica, social e ambiental; aprimorar o relacionamento e a comunicação com todas } \\
\text { as partes interessadas; minimizar os riscos estratégicos, operacionais e financeiros; e aumentar o valor da } \\
\text { Companhia, viabilizando a estratégia de captação de recursos" (COPEL, 2007) [Grifo nosso]. }\end{array}$ \\
\hline & $\begin{array}{l}\text { "A Perdigão adota práticas de gerenciamento para minimizar os riscos aos quais está exposta. Entre os principais } \\
\text { riscos estão os de ordem operacional: mercados de atuação, controle sanitário, grãos, segurança alimentar, } \\
\text { proteção ambiental, controles internos e riscos financeiros, cujo detalhamento se encontra na nota explicativa } 16 \\
\text { das Demonstrações Financeiras" (PERDIGÃO, 2007) [Grifo nosso]. }\end{array}$ \\
\hline
\end{tabular}

Fonte: dados da pesquisa.

A EMBRAER destaca a criação de uma unidade específica destinada ao gerenciamento de todos os riscos a que a empresa está exposta. Destaca ainda no RA, sua exposição aos riscos estratégicos, legais, de mercado, financeiros e operacionais.

O RA da empresa COPEL evidencia a exposição da empresa aos riscos estratégicos, operacionais e financeiros. Destaca a preocupação com o gerenciamento destes riscos no longo prazo, buscando a perenidade da organização. Informa ainda sua estratégia de gestão de riscos, para aumentar o valor da companhia e viabilizar a captação de recursos no mercado de capitais.

A Perdigão destaca a adoção de práticas de gerenciamento de riscos para minimizar seus níveis de exposição. Além da evidenciação dos riscos de exposição da empresa, indica onde nas demonstrações financeiras os acionistas poderão obter maiores informações sobre esses riscos.

Para o COSO (2004), a observância dos eventos prováveis de ocorrência deve considerar fatores internos e externos ao ambiente da empresa. Nesta fase, inicialmente a empresa deve relacionar todos os eventos possíveis de ocorrência, não se preocupando com a sua classificação, o que será realizado na fase de avaliação de riscos. Com relação ao processo de identificação de riscos, o COSO (2004) alerta para a observância de quatro fatores-chave: fatores que influenciam as estratégias e os objetivos da organização, a metodologia e/ou técnica utilizada para a identificação de eventos, a interdependência de eventos, a distinção entre riscos e oportunidades.

\subsubsection{Avaliação dos riscos}

Identificados os riscos, estes precisam ser avaliados para que possam ser monitorados e mitigado seu impacto na organização. Na avaliação de riscos os gestores avaliam a probabilidade de ocorrência dos eventos e seu impacto no alcance dos objetivos da organização. Ramamoorti e Weidenmier (2006, p. 2) citam que a avaliação de risco é "um processo contínuo de calcular a probabilidade de ocorrência de eventos e o impacto deles na organização. Probabilidade é a possibilidade que um evento ocorrerá, enquanto impacto é o resultado financeiro do evento".

No Quadro 5 apresentam-se trechos dos RA das empresas Brasil Telecom Participações S.A., Banco Bradesco S.A. e Aracruz Celulose S.A., para exemplificar o uso da avaliação de riscos na evidenciação da gestão de riscos previstos no COSO. 
Quadro 5 - Componente do gerenciamento de riscos do COSO - Avaliação dos riscos

\begin{tabular}{|c|c|}
\hline $4^{\circ}$ Componente & Exemplos de trechos dos RA das empresas pesquisadas \\
\hline \multirow{3}{*}{$\begin{array}{l}\text { Avaliação } \\
\text { dos riscos }\end{array}$} & $\begin{array}{l}\text { "Em 2007, as provisões para contingências trabalhistas, fiscais e cíveis totalizaram } \mathrm{R} \$ 649,7 \text { milhões, com um } \\
\text { aumento de } \mathrm{R} \$ 162,5 \text { milhões em comparação a } 2006, \text { devido, basicamente à atualização monetária e ao registro } \\
\text { do aumento do risco de perdas em causas trabalhistas, cíveis e tributárias" (BRASIL TELECOM PARTICIPAÇÕES, } \\
\text { 2007) [Grifo nosso]. }\end{array}$ \\
\hline & $\begin{array}{l}\text { "A melhoria na qualidade dos créditos foi confirmada, no final do exercício, pelo aumento do volume de créditos } \\
\text { classificados entre "AA" e "C" e pela redução dos níveis de inadimplência nas pessoas físicas e nas micro, } \\
\text { pequenas e médias empresas, conseqüência da estratégia de privilegiar operações com menor risco de crédito, } \\
\text { como consignados, leasing/CDC veículos, e pelo permanente aperfeiçoamento dos modelos de concessão e } \\
\text { acompanhamento de crédito" (BRADESCO, 2007) [Grifo nosso]. }\end{array}$ \\
\hline & $\begin{array}{l}\text { "A Aracruz considera a gestão de riscos um instrumento essencial para otimizar o uso } \\
\text { melhores oportunidades de negócios, de forma a obter a melhor relação risco } x \text { ret } \\
\text { (ARACRUZ CELULOSE S. A., 2007) [Grifo nosso]. }\end{array}$ \\
\hline
\end{tabular}

Fonte: dados da pesquisa.

A Brasil Telecom Participações evidencia em seu RA o aumento das provisões de contingências em causas trabalhistas, fiscais e cíveis, no período de 2007. Nota-se a preocupação da empresa em destacar as causas do referido aumento, apresentando uma justificativa aos seus acionistas. A empresa alerta que a empresa está exposta a riscos legais e que estes riscos aumentaram de 2006 para 2007, o que indica monitoramento e avaliação de riscos.

No RA do Bradesco verifica-se a preocupação em avaliar os riscos de crédito. Como se pode observar, ao final do período, a empresa apresenta a melhoria dos níveis de classificação destes riscos (redução), destacando o êxito da estratégia utilizada pela administração para a gestão dos riscos de crédito, o que respalda a política de gestão de riscos da organização.

A empresa Aracruz destaca a importância da gestão de riscos para a organização, o que indica a utilização da gestão de riscos na avaliação dos negócios da empresa. A empresa informa ao mercado que a otimização do uso de capital e a seleção das melhores oportunidades são estratégias adotadas pela empresa para avaliar seus níveis de exposição aos riscos do negócio. A empresa relaciona ainda a avaliação destes riscos, a estratégia de obter a melhor relação risco versus retorno aos acionistas, buscando assim maximizar seus resultados.

Para o COSO (2004), o processo de avaliação de riscos deve considerar tanto riscos intrínsecos, como riscos residuais. Também deve estimar a probabilidade de ocorrência e o impacto destes riscos no alcance dos objetivos da empresa. Outro fator destacado pelo COSO (2004) é a importância da mescla de técnicas quantitativas e qualitativas na definição da metodologia a ser utilizada para a identificação dos eventos.

\subsubsection{Resposta ao risco}

Realizada a identificação de eventos e a avaliação dos riscos a que a organização está exposta, inicia-se o processo de resposta ao risco. Nesta etapa o objetivo não é a eliminação total dos riscos, mas sim, a mitigação dos seus efeitos, trazendo-os para níveis aceitáveis.

No Quadro 6 apresentam-se trechos dos RA das empresas Telemig Celular Participações S.A., Sadia S.A. e Companhia Paranaense de Energia (COPEL) para exemplificar o uso da resposta ao risco na evidenciação da gestão de riscos previstos no COSO.

Quadro 6 - Componente do gerenciamento de riscos do COSO - Resposta ao risco

\begin{tabular}{|c|c|}
\hline $\begin{array}{l}5^{\circ} \text { Componente } \\
\text { do COSO }\end{array}$ & Exemplos de trechos dos RA das empresas pesquisadas \\
\hline \multirow{3}{*}{$\begin{array}{l}\text { Resposta } \\
\text { ao risco }\end{array}$} & $\begin{array}{l}\text { "No final de } 2007, \text { o saldo de endividamento da Companhia era de R } \$ 147,9 \text { milhões, sendo que R } \$ 141,7 \text { milhões } \\
\text { estavam contratados em dólar norte-americano. Este valor estava protegido por operações de hedge, cujo objetivo } \\
\text { é reduzir os riscos de variações cambiais" (TELEMIG, 2007) [Grifo nosso]. }\end{array}$ \\
\hline & $\begin{array}{l}\text { "Como estratégia para manter-se competitiva e reduzir o risco de suas operações, a Sadia investiu na ampliação } \\
\text { de seu portfólio de produtos, principalmente de empanados de frango e processados de suínos" (SADIA, 2007) } \\
\text { [Grifo nosso]. }\end{array}$ \\
\hline & $\begin{array}{l}\text { "[...] o Programa de Gestão de Segurança e Saúde do Trabalho - GSST, sistema de controle para eliminação de } \\
\text { riscos existentes no ambiente, atendimento à legislação, treinamento, padronização de atividades de risco, } \\
\text { inspeções, estabelecimento de metas e campanha permanente, o qual está em plena consonância com as } \\
\text { diretrizes da Organização Internacional do Trabalho - OIT" (COPEL, 2007) [Grifo nosso]. }\end{array}$ \\
\hline
\end{tabular}

Fonte: dados da pesquisa. 
A empresa Telemig evidencia a estratégia adotada para responder aos riscos financeiros. Observa-se que a Telemig adota uma política de hedge, a fim de reduzir os riscos de exposição. A informação detalhada pela empresa assegura ao mercado a tranqüilidade frente às operações de endividamento contratadas em moeda estrangeira.

A empresa Sadia demonstra a preocupação da administração em informar ao mercado o objetivo de redução dos riscos de suas atividades. A empresa divulga a estratégia adotada para a mitigação destes riscos (ampliação do portfólio de produtos), o que demonstra uma preocupação da administração para com esse risco especificamente.

A COPEL evidencia em seu RA a preocupação em eliminar os riscos existentes no ambiente de trabalho. Para tanto, a empresa está implantando um programa específico de gestão de segurança e saúde do trabalho, o que vem assegurar a adequação às questões legais e possibilitar melhores condições operacionais de trabalho na organização.

O COSO (2004) estabelece quatro tipos de resposta ao risco: evitar, reduzir, aceitar e compartilhar. Os gestores devem optar pela melhor opção a fim de assegurar que os objetivos estabelecidos sejam alcançados com sucesso. Shenkir e Walker (2001) mencionam que as respostas aos riscos variam de empresa para empresa. Uma organização com a mesma atividade que outra poderá responder aos riscos de forma diferente, levando em consideração seus níveis específicos de exposição.

\subsubsection{Atividades de controle}

No que concerne às atividades de controle, o $\operatorname{COSO}(2004$, p. 67) explicita que "as atividades de controle são as políticas e os procedimentos que contribuem para assegurar que as respostas aos riscos sejam executadas". As atividades de controle são fundamentais ao sistema de gestão de riscos da organização. São os controles implementados pela administração da empresa que monitorarão os riscos a que a entidade está exposta.

No Quadro 7 apresentam-se trechos dos RA das empresas Companhia Energética de Minas Gerais (CEMIG), União de Bancos Basileiros S.A. (UNIBANCO) e Banco Itaú Holding Financeira S.A. para exemplificar o uso das atividades de controle na evidenciação da gestão de riscos previstos no coso.

Quadro 7 - Componente do gerenciamento de riscos do COSO - Atividades de controle

\begin{tabular}{|c|c|}
\hline $6^{\circ}$ Componente & Exemplos de trechos dos RA das empresas pesquisadas \\
\hline \multirow{3}{*}{$\begin{array}{l}\text { Atividades } \\
\text { de controle }\end{array}$} & $\begin{array}{l}\text { "Os instrumentos derivativos contratados têm o propósito de proteger as operações da Companhia contra os riscos } \\
\text { decorrentes de variação cambial e não são utilizados para fins especulativos. As contratações das operações } \\
\text { consideram aspectos de liquidez do mercado, preço relativo dos ativos e a concentração do serviço da dívida" } \\
\text { (CEMIG, 2007) [Grifo nosso]. }\end{array}$ \\
\hline & $\begin{array}{l}\text { "Por meio de uma metodologia proprietária de cálculo e alocação de capital econômico, a área consolida riscos e } \\
\text { contribui para a otimização da relação risco/retorno do Unibanco. Nesse contexto, o gerenciamento do risco de } \\
\text { mercado e liquidez é efetuado através do monitoramento diário dos níveis de exposição frente aos limites } \\
\text { estabelecidos, valendo-se de instrumentos como o VaR, análise de sensibilidade e stress testing" (UNIBANCO, } \\
2007 \text { ) [Grifo nosso]. }\end{array}$ \\
\hline & $\begin{array}{l}\text { "A Auditoria Interna Corporativa tem sua atuação voltada para temas que representam potencial de risco mais } \\
\text { elevado e para a avaliação dos sistemas de controles internos e gerenciamento de riscos, oferecendo ao Comitê } \\
\text { visão crítica sob a perspectiva corporativa. A Auditoria Interna Operacional tem por objetivo a aferição da qualidade } \\
\text { dos processos e o monitoramento à distância dos riscos" (ITAÚ, 2007) [Grifo nosso]. }\end{array}$ \\
\hline
\end{tabular}

Fonte: dados da pesquisa.

Observa-se no trecho apresentado da CEMIG que uma das formas de controle de riscos da empresa é a contratação de derivativos no mercado de capitais. Com a adoção desta medida, a CEMIG busca proteger seus ativos contra os efeitos de uma eventual variação cambial.

A administração do Unibanco evidencia em suas atividades de controle a utilização de instrumentos como Value at Risk (VaR), análise de sensibilidade e stress testing, para o monitoramento e controle das atividades. Além destes instrumentos de controle utilizados, a empresa estabeleceu uma metodologia própria para o cálculo da alocação de capital, buscando melhor rentabilidade. Destaca que tais controles são monitorados constantemente pela área de gestão de riscos. 
O Banco Itaú evidencia que mantém uma unidade destinada à avaliação dos sistemas de controle interno e gerenciamento de riscos, mas não detalha os controles utilizados. Porém, cita duas atividades de controle: aferição da qualidade dos processos e monitoramento dos riscos.

O COSO (2004, p. 67) explicita que as atividades de controle ocorrem “em toda a organização, em todos os níveis e em todas as funções, pois compreendem uma série de atividades - tão diversas, como aprovação, autorização, verificação, reconciliação e revisão do desempenho operacional, da segurança dos bens e da segregação de responsabilidades". Por meio da revisão periódica das atividades de controle é possível readequar processos da organização, a fim de assegurar a eficiência do sistema de gestão de riscos implantado.

\subsubsection{Informação e comunicação}

O ambiente de informação e comunicação estabelecido pelo COSO (2004) está voltado a orientar os gestores da organização para a importância do gerenciamento das informações da empresa, bem como sua comunicação interna e externa. Nesta etapa a administração busca assegurar que as informações desejadas sejam geradas de forma hábil, útil e oportuna. Beuren (1998) destaca como um dos grandes desafios da utilização da informação para a tomada de decisão, a capacitação dos gestores em utilizar a informação para alcançar os objetivos propostos. Outro aspecto é o acesso à informação, ou seja, a comunicação destas informações, aos seus diferentes usuários.

No Quadro 8 apresentam-se trechos dos RA das empresas Tele Norte Leste Participações S.A., Banco Bradesco S.A. e Brasil Telecom Participações S.A., para exemplificar o uso da informação e comunicação na evidenciação da gestão de riscos previstos no COSO.

Quadro 8 - Componente do gerenciamento de riscos do COSO - Informação e comunicação

\begin{tabular}{|c|c|}
\hline $\begin{array}{l}7^{\circ} \text { Componente } \\
\text { do COSO }\end{array}$ & Exemplos de trechos dos RA das empresas pesquisadas \\
\hline \multirow{3}{*}{$\begin{array}{l}\text { Informação e } \\
\text { comunicação }\end{array}$} & $\begin{array}{l}\text { "Responsável pela aprovação e divulgação das informações, as ações do Comitê de Divulgação são } \\
\text { baseadas nos princípios das melhores práticas de Governança Corporativa. Uma série de medidas foram } \\
\text { implementadas para garantir procedimentos adequados de divulgação. A revisão do Regimento Interno do } \\
\text { Comitê de Divulgação, Comunicação, Controles Internos e Gestão de Riscos trouxe benefícios e otimização } \\
\text { do Comitê, segregação de atividades e eficiência na divulgação das informações" (TELE NORTE, 2007) } \\
\text { [Grifo nosso]. }\end{array}$ \\
\hline & $\begin{array}{l}\text { "O Banco tem divulgado os fatores de riscos e políticas contábeis críticas, em sintonia com as melhores } \\
\text { práticas internacionais de transparência e governança corporativa e em conformidade com as } \\
\text { demonstrações financeiras no formato americano - US GAAP, relacionadas a prováveis situações político- } \\
\text { econômicas nos mercados nacional e internacional e que podem impactar diretamente o dia-a-dia das } \\
\text { operações e, conseqüentemente, a situação financeira do Banco, disponível no Relatório de Análise } \\
\text { Econômica e Financeira, no site www.bradesco.com.br/ri" (BRADESCO, 2007) [Grifo nosso]. }\end{array}$ \\
\hline & $\begin{array}{l}\text { "Entre as iniciativas adotadas, destacamos: Reforma do Estatuto Social - entre outras mudanças, instituiu o } \\
\text { modelo de gestão colegiada na Diretoria Executiva; Criação de Comitês Técnicos e Consultivos de } \\
\text { assessoramento e avaliação de desempenho do Conselho de Administração; Implementação do modelo de } \\
\text { gestão de riscos; Revisão da política de divulgação e uso de informações, e de negociação de valores } \\
\text { mobiliários da Companhia" (BRASIL TELECOM, 2007) [Grifo nosso]. }\end{array}$ \\
\hline
\end{tabular}

Fonte: dados da pesquisa.

Nota-se a preocupação da administração da empresa Tele Norte em demonstrar seriedade no tratamento e divulgação das informações pertinentes às atividades da empresa. No trecho destacado percebe-se que a empresa possui uma unidade específica que aprova e divulga as informações da empresa. Também se preocupa em evidenciar aos seus acionistas, que as ações do Comitê de Divulgação são baseadas nos princípios das melhores práticas de governança corporativa e que a empresa possui inclusive Regimento Interno.

No caso do Bradesco, nota-se que a empresa apresenta uma política definida de divulgação das informações de seus negócios. Vem divulgando os fatores de riscos, bem como as políticas contábeis críticas, que podem afetar a situação financeira da empresa. Destaca ainda onde o acionista poderá obter tais informações, com o endereço eletrônico de acesso de tais informações, dando maior transparência às informações divulgadas (detalhamento).

A Brasil Telecom informa em seu RA que em 2007 investiu em um novo padrão de governança, a fim de aumentar a credibilidade da empresa no mercado de capitais. Dentre as iniciativas adotadas, a empresa 
informa que revisou sua política de divulgação e uso das informações, mas não menciona a política adotada.

Para o mercado de capitais, esta premissa é fundamental, uma vez que os investidores consideram as informações divulgadas pelas empresas. $O \operatorname{COSO}(2004$, p. 79$)$ alerta para a necessidade da informação ter qualidade, apresentando alguns questionamentos: "O conteúdo é apropriado - está no nível de detalhes adequado? As informações são oportunas - estarão disponíveis quando necessário? As informações são atuais - são as mais recentes? As informações são exatas - os dados estão corretos? As informações são de fácil acesso?".

\subsubsection{Monitoramento}

O último ambiente de controle estabelecido pelo $\operatorname{COSO}$ (2004) é relativo ao monitoramento. De acordo com o $\operatorname{COSO}(2004$, p. 83), "o gerenciamento de riscos corporativos é monitorado, avaliando-se a presença e o funcionamento de seus componentes ao longo do tempo. Essa tarefa é realizada mediante atividades contínuas de monitoramento, avaliações independentes ou uma combinação de ambas". No caso de identificação de situações de riscos, estas devem ser comunicadas à administração da organização, a fim de que possa tomar as medidas necessárias para a mitigação do risco. O sistema de controles das atividades deverá ser revisto e ajustado, em conformidade com a nova determinação.

No Quadro 9 apresentam-se trechos dos RA das empresas Companhia Energética de Minas Gerais (CEMIG), Companhia Siderúrgica Nacional (CSN) e Banco Bradesco S.A., a fim de exemplificar o uso do monitoramento na evidenciação da gestão de riscos previstos no $\operatorname{COSO}$.

Quadro 9 - Componente do gerenciamento de riscos do COSO - Monitoramento

\begin{tabular}{|c|c|}
\hline $8^{\circ}$ Componente & Exemplos de trechos dos RA das empresas pesquisadas \\
\hline \multirow{3}{*}{ Monitoramento } & $\begin{array}{l}\text { "Para aumentar a eficiência de sua atuação, o Conselho constituiu } 5 \text { (cinco) comitês que atuam de forma mais } \\
\text { específica nas questões relacionadas à Estratégia, Governança, Finanças, Auditoria e Riscos e Recursos } \\
\text { Humanos. Em 2007, foram realizadas } 25 \text { reuniões para deliberação sobre diversos assuntos, desde planejamento } \\
\text { estratégico até projetos de investimentos" (CEMIG, 2007) [Grifo nosso]. }\end{array}$ \\
\hline & $\begin{array}{l}\text { "Em dezembro de 2007, com a aprovação do seu Conselho de Administração, a CSN constituiu a área de } \\
\text { Gerenciamento de Riscos Corporativos, na qual possui como sua principal premissa a responsabilidade pela } \\
\text { análise e acompanhamento dos riscos estratégicos, operacionais e financeiros da Companhia" (CSN, 2007) [Grifo } \\
\text { nosso]. }\end{array}$ \\
\hline & $\begin{array}{l}\text { "[...] por meio do seu Comitê de Classificação de Risco, manteve o rating AAA para o Bradesco, pela forte p } \\
\text { financeira no Mercado" (BRADESCO, 2007) [Grifo nosso]. }\end{array}$ \\
\hline
\end{tabular}
Fonte: dados da pesquisa.

A CEMIG demonstra preocupação em aumentar a eficiência de sua atuação. Para tanto, constituiu comitês específicos que auxiliam os administradores no monitoramento das atividades da empresa, bem como, auxiliam o processo decisório. A empresa evidencia ainda o número de reuniões realizadas pelos comitês e o conselho de administração, destacando a importância desses encontros para a deliberação de questões pertinentes a empresa.

No RA da CSN nota-se que apenas em dezembro de 2007 sua administração constituiu uma área específica para o gerenciamento de riscos corporativos, o que pode denotar a inexistência da gestão de riscos anteriormente ou pouca preocupação por parte de sua administração com essa gestão até então. A empresa destaca que essa área tem como premissa a análise, o monitoramento e o gerenciamento dos riscos a que a organização está exposta.

A administração do Banco Bradesco informa neste trecho que possui um Comitê específico responsável pelo monitoramento e classificação dos riscos de crédito da empresa. A empresa ressalta a manutenção do rating AAA de 2006 para 2007, enfatizando que tal resultado foi possível pela forte posição financeira do Bradesco no mercado, o que indica ao acionista que a empresa está com uma posição financeira consolidada.

Ao se estabelecer uma estrutura para o gerenciamento dos riscos da organização, o monitoramento das ações é fundamental, a fim de identificar se os papéis estão sendo executados (cumpridos), bem como as atividades propostas, os controles estabelecidos e, por conseqüência, se os resultados desejados serão alcançados. Gherman (2007) ressalta que o gerenciamento de riscos na organização deve ser monitorado 
em âmbito global e alterado sempre que se fizer necessário. O monitoramento deve ser realizado por meio de atividades contínuas de gestão.

\subsection{Termos de Evidenciação da Gestão de Riscos por Componente do COSO}

A Tabela 1 evidencia os componentes do COSO identificados no decurso da análise de conteúdo dos relatórios da administração das empresas pesquisadas.

Tabela 1 - Termos de evidenciação da gestão de riscos por componente do COSO

\begin{tabular}{|c|c|c|c|c|}
\hline Componentes do COSO & $\begin{array}{c}\text { Número de } \\
\text { observações nos } \\
\text { RA }\end{array}$ & $\begin{array}{c}\text { \% de } \\
\text { observações }\end{array}$ & $\begin{array}{c}\text { Número de } \\
\text { empresas cl } \\
\text { evidenciação }\end{array}$ & $\begin{array}{c}\% \text { de } \\
\text { empresas }\end{array}$ \\
\hline Ambiente Interno & 34 & $8,50 \%$ & 13 & 46,43 \\
\hline Definição (Fixação) de Objetivos & 27 & $6,75 \%$ & 14 & 50,00 \\
\hline Identificação de Riscos & 82 & $20,50 \%$ & 17 & 60,71 \\
\hline Avaliação de Riscos & 62 & $15,50 \%$ & 14 & 50,00 \\
\hline Resposta ao Risco & 26 & $6,50 \%$ & 16 & 57,14 \\
\hline Atividade de Controle & 99 & $24,75 \%$ & 15 & 53,57 \\
\hline Informação e Comunicação & 33 & $8,25 \%$ & 9 & 32,14 \\
\hline Monitoramento & 37 & $9,25 \%$ & 13 & 46,43 \\
\hline Total & 400 & $100,00 \%$ & 28 & $100,00 \%$ \\
\hline
\end{tabular}

Fonte: dados da pesquisa.

Observa-se na Tabela 1 que todos os componentes previstos no coso foram de alguma forma evidenciados nos relatórios da administração pesquisados. O ambiente que apresenta a maior quantidade de termos evidenciados é relativo às atividades de controle, cuja proporção representa $24,75 \%$ do total de termos sobre gestão de riscos evidenciados nos relatórios da administração pesquisados, ou seja, 99 citações.

A maior concentração de evidenciação dos termos da gestão de riscos nos RA foi identificada em três ambientes. Do total de termos evidenciados (400), 243 termos (60,75\%) estão relacionados às atividades de controle, identificação e avaliação de riscos. O ambiente de menor evidenciação é o ambiente de resposta ao risco, com apenas 26 evidenciações (6,50\%), seguido da definição dos objetivos, com 27 evidenciações $(6,75 \%)$.

O número de empresas que evidenciaram itens recomendados em cada um dos componentes do COSO é relativamente baixo. Destaca-se o componente identificação de riscos, com o maior número de empresas $(60,71 \%)$ que evidenciaram algo sobre o mesmo; e no outro extremo o componente informação e comunicação, com o menor número de empresas $(32,14 \%)$ que evidenciaram características desse ambiente.

Um aspecto que chamou atenção na pesquisa é que do total de 28 empresas pesquisadas, apenas sete, ou seja, $25 \%$ da amostra, evidenciaram características superiores a $50 \%$ dos itens recomendados pelo COSO. Ainda, 17 empresas $(60,71 \%)$ evidenciaram características inferiores a $47,66 \%$ das informações básicas preconizadas para cada um dos componentes do COSO. Por outro lado, quatro empresas não evidenciaram a gestão de riscos em seus RA.

\section{Conclusões}

Este estudo objetivou analisar o conteúdo de evidenciação da gestão de riscos, tendo como referência a metodologia do Committee of Sponsoring Organizations of the Treadway Commission (COSO) (2004), nos relatórios da administração das empresas brasileiras com emissão de ADRs na Bolsa de Valores de Nova York (NYSE). Foi realizado estudo descritivo, por meio de pesquisa documental, utilizando-se da técnica da análise de conteúdo, com abordagem quantitativa dos dados. A amostra da pesquisa compreendeu 28 empresas brasileiras com emissão de American Depositary Receipt (ADRs).

Nos relatórios da administração buscou-se analisar o conteúdo de evidenciação da gestão de riscos pela metodologia do COSO (2004), considerando-se como unidade de registro o termo risco e como unidade de contexto a frase. Com relação ao conteúdo de evidenciação dos relatórios da administração analisados, foi 
possível identificar diversas passagens nos RA das empresas pesquisadas que denotam algum tipo de gerenciamento de riscos conforme preconizado na metodologia do COSO (2004).

Identificaram-se nos relatórios da administração pesquisados 400 termos relacionados à gestão de riscos dos ambientes de controle propostos na metodologia do COSO (2004), distribuídos nos oito componentes: ambiente interno (de controle), definição (fixação) de objetivos, identificação dos riscos, avaliação dos riscos, resposta ao risco, atividades de controle, informação e comunicação, monitoramento. O ambiente que apresentou maior evidenciação de termos relacionados à gestão de riscos foi o da atividade de controle, com 99 observações, e o menor foi da resposta ao risco, com 26 observações.

Embora todos os ambientes da metodologia do $\operatorname{COSO}(2004)$ tenham sido evidenciados nos relatórios da administração analisados, a quantidade de empresas que evidenciaram todos os componentes não é expressiva. Observou-se maior número de empresas $(60,71 \%)$ com evidenciação no componente identificação de riscos e menor número de empresas $(60,71 \%)$ com evidenciação no componente informação e comunicação.

Constatou-se também que os ambientes com maior número de observações nos relatórios da administração não guardam relação direta com o maior número de empresas que os evidenciaram. Há empresas que focalizam mais na evidenciação de determinados componentes da metodologia do coso (2004) em seus relatórios de administração do que outras, ainda que não evidenciam todos os componentes.

Com base nos relatórios da administração pesquisados, conclui-se que não há uniformidade entre as empresas na evidenciação de informações a respeito das práticas de gestão de riscos. Em geral, as empresas divulgam ações relativas às atividades de controle e identificação de riscos, mas não indicam como respondem a estes riscos. Para futuros estudos, recomenda-se ampliar a pesquisa para outros meios de divulgação da gestão de riscos inerentes às atividades das empresas, por exemplo nas notas explicativas, relatórios trimestrais, informações anuais, a fim de constatar as semelhanças e divergências nos resultados.

\section{Referências}

ALENCAR, R. C. Nível de disclosure e custo de capital próprio no mercado brasileiro. 2007. 104 fls. Tese (Doutorado em Ciências Contábeis) - Faculdade de Economia, Administração e Ciências Contábeis da Universidade de São Paulo, São Paulo, 2007.

ARACRUZ CELULOSE S. A. Relatório da Administração de 2007. Disponível em: <http://www.aracruz.com.br/minisites/ra2007/section/pt/informacoes_financeiras/df_2008410101516.pdf>. Acesso em: 20 nov. 2008.

BARDIN, L. Análise de conteúdo. Lisboa: Edições 70, 1977.

BEUREN, I. M. Gerenciamento da informação: um recurso estratégico no processo de gestão empresarial. São Paulo: Atlas, 1998.

BEUREN, I. M. O papel da controladoria no processo de gestão. In: SCHMIDT, P. (Org). Controladoria: agregando valor para a empresa. Porto Alegre: Bookman, 2002. p. 15-38.

BOLSA DE VALORES DE SÃO PAULO (BOVESPA). Disponível em: <www.bovespa.com.br>. Acesso em: 20 nov. 2008.

BRASIL. Lei no 6.404, de 15 de dezembro de 1976. Dispõe sobre as sociedades por ações. Diário Oficial [ da] República Federativa do Brasil, Brasília, DF, 17 dez. 1976. Disponível em: <http://www.planalto.gov.br/CCIVIL/LEIS/L6404compilada.htm>. Acesso em:10 out. 2008.

BRASIL. Lei no 11.638, de 28 de dezembro de 2007. Altera e revoga dispositivos da Lei no 6.404 , de 15 de dezembro de 1976, e da Lei o 6.385, de 7 de dezembro de 1976, e estende às sociedades de grande porte disposições relativas à elaboração e divulgação de demonstrações financeiras. Disponível em: <http://www.planalto.gov.br/ccivil_03/_ato2007-2010/2007/Lei/L11638.htm>. Acesso em: 10 out. 2008.

COMISSÃO DE VALORES MOBILIÁRIOS (CVM). Parecer de orientação CVM no 15, de 28 de dezembro de 1987. Disponível em: <http://www.cvm.gov.br>. Acesso em: 10 out. 2008. 
CONSELHO FEDERAL DE CONTABILIDADE (CFC). Princípios fundamentais de contabilidade e normas brasileiras de contabilidade. 2 ed. Brasília: CFC, 2000.

COMMITTEE OF SPONSORING ORGANIZATIONS OF THE TREADWAY COMMISSION (COSO). Enterprise risK management - integrated framework, AICPA, New York, 2004.

COMMITTEE OF SPONSORING ORGANIZATIONS OF THE TREADWAY COMMISSION (COSO). Internal control integrated framework, AICPA, New York, 1992.

COMITÉ DE PRONUNCIAMENTOS CONTÁBEIS (CPC). Estrutura conceitual básica. Disponível em: < http://www.cpc.org.br/index.php>. Acesso em: 10 out. 2008.

INSTITUTO DE PESQUISAS CONTÁBEIS, ATUARIAIS E FINANCEIRAS (FIPECAFI). Manual de contabilidade das sociedades por ações: aplicável às demais sociedades. 5. ed. São Paulo: Atlas, 2000.

FREITAS, H. M. R.; CUNHA JÚNIOR, M. V. M.; MOSCAROLA, J. Aplicação de sistema de software para auxílio na análise de conteúdo. Revista de Administração da Universidade de São Paulo, v. 32, n. 3, p. 97-109, jul./set., 1997.

FREITAS, H.; JANISSEK, R. Análise léxica e Análise de conteúdo: técnicas complementares, seqüenciais e recorrentes para análise de dados qualitativos. Porto Alegre: Sphinx, 2000.

GHERMAN, M. Controles internos: buscando a solução adequada. 2007. Disponível em: http://www.moduloriskmanager.com.br/artigo_10.htm. Acesso em: 15 out. 2008.

GIL, A. C. Como elaborar projetos de pesquisa. 4. ed. São Paulo: Atlas, 2002.

GOULART, A. M. C. Evidenciação contábil do risco de mercado por instituições financeiras no Brasil. 2003. 201 f. Dissertação (Mestrado em Controladoria e Contabilidade) - Curso de Pós-Graduação em Controladoria e Contabilidade, Faculdade de Economia, Administração e Contabilidade da Universidade de São Paulo, São Paulo, 2003.

HENDRIKSEN, E. S.; VAN BREDA, M. F. Teoria da contabilidade. São Paulo: Atlas, 1999.

IUDÍCIBUS, S. Teoria da contabilidade. 7. ed. São Paulo: Atlas, 2004.

JORION, P. Value at risk. Nova York: Wiley, 1997.

MAIA, M. S.; SILVA, M. R.; DUEÑAS, R.; ALMEIDA, P. P.; MARCONDES, S.; CHING, H. Y. Contribuição do sistema de controle interno para a excelência corporativa. Revista Universo Contábil, v. 1, n. 1, p. 54-70, jan./abr., 2005.

NIYAMA, J. K.; GOMES, A. L. O. Contribuição ao aperfeiçoamento dos procedimentos de evidenciação contábil aplicáveis às demonstrações financeiras de bancos e instituições assemelhadas. Anais... XV Congresso Brasileiro de Contabilidade, Brasília, 2006.

NEW YORK STOCK EXCHANGE (NYSE). NYSE Marke Trac. Disponível em: <http://www.nyse.com/about/listed/lc_all_region_4.html?ListedComp =All\&country $=7 \&$ start $=1 \&$ startlist $=1 \& \mathrm{i}$ tem $=1 \&$ prev $=$ clicked \&firsttime $=$ done $\&$ default $=\overline{1}>$. Acesso em: 19 set. 2008.

QUINTEIRO, L. G. L. A relação entre a evidenciação de informações contábeis e a volatilidade dos retornos das ações no Brasil. In: CLADEA, 39., 2004, República Dominicana. Anais... República Dominicana: CLADEA, 2004. CD-ROM.

RAMAMOORTI, S.; WEIDENMIER, M. Is close for ERM? The Internal Auditor. v. 63, n. 2, p. 45-51, apr., 2006.

SHENKIR, W. G.; WALKER, P. L. Administration of risk of enterprise and the strategy-risk-focused organization. Cost Management, v. 20, n. 3, p. 32-39, may/jun., 2001.

SILVA, A. M. B. A gestão de risco. Revista Auditoria Interna, v.6, n. 21, p. 8-12, jul./ago. 2005.

SILVA, C. A. T.; RODRIGUES, F. F.; ABREU, R. L. Análise dos relatórios de administração das companhias abertas brasileiras: um estudo do exercício social de 2002. In: ENANPAD, 28., 2004, Curitiba. Anais... Rio de Janeiro: ANPAD, 2004. CD-ROM.

SOUZA, C. Adaptação e aplicação de práticas de gestão de riscos e controles internos em instituições de ensino superior do estado de Santa Catarina. 2007. 150 fls. Dissertação (Mestrado em Ciências Contábeis) Universidade Regional de Blumenau, Blumenau, 2007. 